\title{
O lugar do hospital psiquiátrico na atualidade: da disciplina ao abandono
}

\section{The place of the psychiatric hospital at the present time: from the discipline to abandonment}

\author{
Fernando Sfair Kinker ${ }^{1}$
}

KINKER, F. S. O lugar do hospital psiquiátrico na atualidade: da disciplina ao abandono. Rev. Ter. Ocup. Univ. São Paulo, v. 23, n. 2, p. 172-185, maio/ago. 2012.

RESUMO: Este artigo traz uma reflexão sobre o lugar que o hospital psiquiátrico ocupa na atualidade. Partindo da experiência de desconstrução de um hospital psiquiátrico em Campina Grande, Paraíba, no ano de 2005, discute que o manicômio atual funciona nem tanto a partir de uma lógica disciplinar, que acompanhou durante anos o desenvolvimento do asilo, mas de uma nova lógica do abandono, em sintonia com as novas formas de desregulamentação que caracterizam os novos padrões de sociabilidade dos tempos atuais. O abandono surge como um método de controle das instituições segregadoras que funciona em sintonia com as novas formas capilares e desregulamentadas de controle. Por fim, discute-se a necessidade de um pensar crítico sobre a forma de sociabilidade da modernidade, como um passo importante para a desconstrução do paradigma psiquiátrico.

DESCRITORES: Desinstitucionalização; Reforma dos serviços de saúde; Unidade hospitalar de psiquiatria.

\footnotetext{
* Este trabalho faz parte de uma dissertação de mestrado em ciências sociais, defendida na PUC-SP em 2007.

1. Professor Doutor do curso de Terapia Ocupacional da UNIFESP - Baixada Santista.

Endereço para correspondência: UNIFESP - Av. D. Ana Costa, 95 -Vila Mathias - Santos - CEP: 11060-001.
} 
$\mathrm{O}$ intuito deste artigo é trazer algumas reflexões em torno da experiência prática de desconstrução de um hospital psiquiátrico ocorrida entre abril e julho de 2005 na cidade de Campina Grande, Paraíba (KINKER, 2007). A partir de uma intervenção determinada pela justiça federal, a pedido do Ministério da Saúde, desenvolveu-se um processo de desmontagem e de reconversão de recursos na implantação de serviços territoriais e comunitários, acompanhado por uma intensa luta conceitual, técnica, política e econômica. $\mathrm{O}$ objetivo não é relatar a experiência, na qual o autor ocupou o papel de interventor federal, mas informar ao leitor que as reflexões aqui apresentadas são oriundas essencialmente de uma prática, de uma experiência. São também parte da dissertação de mestrado que abordou a questão a partir da articulação entre alguns referenciais, como a perspectiva teórica da desinstitucionalização, as discussões sobre a complexidade nas ciências, questões referentes ao poder e à crítica à sociabilidade constituída em torno da mercadoria. A partir do relato sobre o processo de desconstrução do hospital, apresentado sob a forma de diário de campo, desenvolveu-se a discussão sobre o lugar do hospital psiquiátrico, que agora será apresentada (KINKER, 2007).

\section{O lugar do hospital psiquiátrico na atualidade}

A questão fundamental que se coloca é saber qual o lugar social que o hospital psiquiátrico ocupa na atualidade, tendo em vista que as condições de absoluta anomia dos atuais hospitais, que parecem mais campos de refugiados sem qualquer condição mínima de sobrevivência do que equipamentos de saúde, parecem indicar que a perspectiva reabilitadora e disciplinar há muito foram abandonadas.

Afinal, há muito não estamos numa sociedade puramente disciplinar (FOUCAULT, 2000, 2005), que inventou o manicômio e o desenvolveu em sintonia com as instituições que promoviam uma nova forma de estar no mundo centrada no trabalho assalariado ${ }^{(1)}$. Como ressaltou Deleuze (1992), a partir do pós-guerra, as formas de combater os desvios, as diferentes instituições e dispositivos de controle também se transformaram. As formas de combate aos desvios flexibilizaram-se e formas mais capilares de controle social pouco a pouco passaram a conviver com a pura segregação dos espaços fechados.

Caberia refletir se os manicômios possuem uma função específica na sociedade de controle (DELEUZE, 1992), ou se eles seriam apenas resquícios de uma sociedade disciplinar em extinção, o que, portanto, os levaria também a um processo futuro de extinção.

A discussão sobre as variadas formas de controle ou de combate aos desvios, desde as mais violentas e explícitas às mais maleáveis e contínuas, não é nova.Basaglia (1977) já apontava que, a cada degrau do desenvolvimento tecnológico e produtivo da sociedade capitalista, correspondiam estratégias mais ou menos diferenciadas de dominação e manipulação, de modo que o nível da estrutura econômica e a organização institucional sempre coincidiam. Por isso, não era à toa que o manicômio enquanto tal tivesse se estruturado no início da revolução industrial. Em países mais desenvolvidos, apontava ele (1977), como era o caso dos EUA, já se percebia que o caráter mais comunitário das ações de combate aos desvios (que deu origem à psiquiatria comunitária ou preventiva) estava associado às formas de segregação no manicômio e no cárcere. Nos países europeus, a tendência à utilização das instituições segregadoras surgia não só como resposta concreta à necessidade de separar os indesejáveis, mas como perpétua ameaça aos que um dia pudessem desviar. Basaglia assinalava ainda que, nos países menos desenvolvidos da América do Sul, na época das ditaduras, a tortura podia institucionalizar-se como prática e como ameaça, convivendo com a segregação, já que a ameaça isolada de segregar em asilos não funcionava tão bem em situações de vida desafortunadas, onde muitos não tinham o que comer nem onde dormir, e onde não havia nenhum movimento forte de contestação e de luta capaz de explicitar as contradições (BASAGLIA, 1977).

A noção de norma e o conceito de homem acompanham esses processos de desenvolvimento econômico. E é em nome desses conceitos abstratos de homem, em detrimento do homem real, com suas necessidades reais, que se constroem as formas de combater os desvios $^{(2)}$. Em nome desse homem abstrato é que existe o

\footnotetext{
(1) Para Deleuze (1992), a sociedade de controle caracteriza-se por fluxos de poder maleáveis e não pela rigidez das estruturas disciplinares, e por uma capilarização acentuada do controle, pela inclusão mais que pela exclusão. Nela, a prisão dá lugar a penas alternativas, permitindo a vigilância em espaços e tempos ininterruptos; o hospital vira hospital-dia, e passa a ocupar os corpos e as mentes de maneira permanente, e não só em momentos especiais; a educação e o controle pedagógico saem dos espaços escolares na tentativa de disseminar seu poder normativo em todos os poros da sociedade. A empresa, com seus sistemas de prêmios e de competição, substituiu a fábrica; a formação permanente tomou o lugar da escola, e o controle contínuo o do exame. (2) Basaglia afirma que a psiquiatria simplifica a existência-sofrimento do doente, colocando-o entre parênteses,para se dedicar à definição abstrata de uma doença. (BASAGLIA,1985). Ela só se relaciona com a doença e não com o sujeito, e para isso tem respostas prontas, construídas sobre a nosografia das doenças, sem dar espaço para que as perguntas, as necessidades reais e a experiência existencial do doente apareçam. Para ele, "liberar as necessidades reais do usuário de um serviço, das necessidades artificiais, produzidas de tal maneira que a resposta à necessidade se traduza no controle da classe subordinada, significa romper este mecanismo e fazer explícita, na prática, a função da ideologia científica como suporte falsamente neutro da ideologia dominante"(BASAGLIA; BASAGLIA, 1977 p. 17).
} 
progresso das ciências e da civilização, diz Basaglia (1977).

\section{trabalho}

Por que é necessário o manicômio: a questão do

A questão da necessidade atual do manicômio é muito complexa, e não se pode ter a pretensão nem haveria condições teóricas de esgotá-la aqui. Contudo, algumas das reflexões trazidas pela experiência, esta sim passível de ser investigada, podem tocar em aspectos importantes da questão.

As mudanças relativas ao lugar do trabalho e à centralidade que este sempre ocupou na vida social continuam a se relacionar com o papel desempenhado hoje pelo manicômio. Houve muitas mudanças no mundo do trabalho desde o surgimento da industrialização nas sociedades ocidentais. Hoje não são mais necessárias técnicas disciplinares para inculcar nos sujeitos a importância do trabalho e a disposição para executá-lo, como foi preciso fazer na época de consolidação da sociedade disciplinar. (BAUMAN, 2003). Enquanto as sociedades foram adaptando os modos de vida às necessidades do trabalho e do mercado, o avanço das forças produtivas, o desenvolvimento da microeletrônica e as novas técnicas de gerenciamento de pessoal no decorrer do século XX aumentaram a produção mas ampliaram o desemprego, não obstante os surtos de crescimento que, em alguns momentos, incrementaram os postos de trabalho. Mas a possibilidade de crescimento da empregabilidade e do consumo é sempre limitada, devido a vários fatores econômicos: dificuldade de angariar investimentos, pois o capital volátil procura se reproduzir pela especulação nas bolsas; distribuição desigual de riquezas que afeta a capacidade geral de consumo; limitação nas inovações de produtos num ambiente em que há uma inflação de necessidades artificiais de consumo já criadas; substituição do homem produtor pela tecnologia de ponta. Atualmente se vê o desemprego estrutural e não pontual se impor fortemente no momento mesmo em que a ideia de que o trabalho é a base da organização dos modos de vida já está consolidada (KURZ, 1993). O aumento na procura por trabalho e a diminuição da oferta de empregos têm levado a uma forte precarização geral das condições de trabalho.

Ao mesmo tempo, os Estados parecem adotar a posição contrária aos investimentos nas políticas de inclusão social que seguem a lógica do Estado de bem-estar social, alegando que estas ficaram muito custosas e prejudicam a atual dinâmica de crescimento do mercado que gera mais riquezas para esses mesmos Estados (ANDERSON, 2007).

Está mais presente que nunca a tendência de tornar os trabalhadores peças descartáveis, o que vem sendo acompanhado de mudanças nas formas de hierarquia nas próprias empresas.(BAUMAN, 2003; SENNETT, 2006)

O sociólogo Bauman (2003) constrói uma bela metáfora sobre essa questão, quando diz que, em várias situações, como a das empresas atuais, por exemplo, em vez de se providenciar tecnologias disciplinares que organizem hierarquicamente os trabalhadores em pelotões ou colunas em marcha, a ser milimetricamente vigiados por chefes e subchefes, como num regime panóptico (FOUCAULT, 2008), é mais comum encontrar uma nova configuração em forma de enxames, onde os trabalhadores, por si sós, seguem as normas da empresa, concorrendo entre si, movidos pela sedução da premiação, pela incerteza e insegurança em que o passado meritório não garante o futuro, pela necessidade de demonstrar fervor à empresa, sem necessidade de controles rígidos (BAUMAN, 2003). O movimento se dá de forma inversa: em vez de se intervir e impor aos trabalhadores normas e modos de ação, exercendo uma força disciplinar, são os próprios trabalhadores que passam a perseguir a direção esperada pela empresa e a se movimentar em direção a ela.

Acrescentando algo a essa imagem de Bauman, pode-se lembrar que as condições flexíveis de trabalho, no que diz respeito aos horários e ao trabalho empresarial que, em algumas situações, pode ser realizado nos domicílios dos trabalhadores, só fazem aumentar ainda mais a produtividade, diminuindo o número de trabalhadores inseridos no mercado formal de trabalho.

O trabalho informal também se multiplica, enquanto os programas de transferência de renda para a população de baixa renda, no caso de países como o Brasil, cada vez encontram mais dificuldades para inserir seus usuários no mercado de trabalho, pois fica claro que a qualificação exigida pelas empresas não para de aumentar.

Essa lógica de descartabilidade das pessoas no mercado corrobora a alegada necessidade de haver espaços para incluir os refugos, para além das técnicas de controle flexíveis. Isso porque o desemprego em massa causa distúrbios sociais difíceis de contornar apenas com dispositivos de controle flexíveis, dispostos capilarmente nos espaços sociais.

A função do manicômio, vinculada à defesa dos padrões de existência pautados no trabalho, não é novidade. A invenção do manicômio, pelo menos em parte, pode ser explicada pela necessidade de consolidar as normas e modos de vida inaugurados pelo trabalho assalariado. Assim, outros fatores, característicos da atualidade, devem ajudar a explicar a necessidade da existência do manicômio hoje. Um deles pode ser atribuído a desregulamentação imposta como padrão em todos os âmbitos da existência e da vida 
em sociedade.

\section{Por que o manicômio é necessário: a desregulamentação}

A desregulamentação como regra, que passa pelo mundo do trabalho, mas também o ultrapassa, apontada por autores que tentam caracterizar a sociedade pós-moderna é um fator que fala a favor da necessidade de um espaço de reclusão nas sociedades de controle flexível. Ela faz parte de um mundo fluido, líquido, onde o consumo assume centralidade (BAUMAN, 1998, 2004).

A desregulamentação é geradora de insegurança. Todo o investimento que as instituições da sociedade disciplinar fizeram para enraizar as populações em modos de vida estáveis, centrados no trabalho e no mercado, e mediado pelos Estados, agora é descartado e toda a sua construção desaba como um castelo de cartas de baralho. (BAUMAN, 2003)

A velocidade das mudanças é acelerada e muitos dos pontos de referência se modificam constantemente: os valores culturais e morais; a forma de funcionamento e o tipo de respostas das instituições; as formas de se obter o ganho material que garante a sobrevivência. $\mathrm{O}$ que poderia parecer a possibilidade de usufruir um grau elevado de liberdade é vivido como exasperação, angústia e insegurança. Essa virtualização das referências, associada a todo o processo tecnológico das empresas, mas também assentada nas mudanças da percepção do espaço e do tempo que o aumento das velocidades da comunicação e do transporte propiciaram, produz um aumento da insegurança.

Esse novo tipo de insegurança difere da vivida pelos camponeses que deixavam os feudos e chegavam às cidades quando do início da industrialização, e faz os indivíduos perderem o chão e clamarem por autoridade, por estruturas antes conhecidas que aos poucos vão desaparecendo (CASTEL, 1998). A insegurança de quem se sente andando em areias movediças produz a necessidade de espaços estáveis e estanques, de instituições que possam simbolicamente representar uma referência sólida ou que concretamente se fechem sobre si mesmas.

Instituições totais ${ }^{(3)}$ (GOFFMAN, 1974) podem tornar-se um simulacro de solução tanto para os desafortunados quanto para aqueles que se movem muito bem na instabilidade das areias movediças, mas que não suportam presenciar outras pessoas afundando em areias tão volumosas.
Instituições totais podem ser então um contraponto necessário à instabilidade permanente dos processos sociais. Elas sabem muito bem se combinar com a fluidez perene dos controles ininterruptos.

Contudo, tais instituições, que se combinam aos mecanismos de controle flexível, assumem características diferentes daquelas que expressavam sua vocação disciplinar, já que sua função como máquina de combate aos desvios também se modificou. Esses espaços, para além de recuperar e disciplinar cuidadosamente, como era o desejo dos alienistas, podem ser espaços inertes, passíveis de serem usados ou rapidamente descartados, dependendo das circunstâncias, o que os caracterizaria como uma forma de dispositivo segregador adaptado a uma sociedade como a de controle.

Em outras palavras, os manicômios e os demais espaços de confinamento podem ser depósitos de pessoas, que lá chegam voluntariamente ou à força e, dependendo da situação existencial, elas próprias e suas famílias podem desejar ativamente uma internação perpétua - o que é comum no Brasil. Contudo, o que encontram como resposta a seu pedido de cuidado e abrigo, que pode resgatar a sensação de segurança perdida, é nada mais que o abandono.

\section{Da "lógica disciplinar" à "lógica do abandono"}

As reflexões sobre a experiência no hospital psiquiátrico levam a constatação de que o abandono se reproduz no interior do manicômio, configurando uma situação em que parece não haver nenhuma expectativa de melhorar os pacientes, ou de inseri-los novamente nas suas comunidades. É como se a própria autoridade científica do manicômio enquanto espaço de tratamento, um dos polos da função psiquiátrica que convive com o outro polo associado ao controle, compondo, segundo Castel (1977), a "contradição psiquiátrica", tivesse sido abandonada, e como se a des-responsabilização sobre o presente e o futuro dos pacientes tivesse sido assumida, na prática mas não no discurso, pela própria psiquiatria e pelas famílias dos doentes. Se configura a situação de inércia gerada pela lógica do abandono, situação ambígua, uma vez que se reforça o polo da função de controle social por meio da tecnologia do abandono. Ou seja, o controle pelo abandono.

Nesse sentido, internar ou não um doente mental pode ser uma alternativa entre outras, pois há outras formas de abandono, como deixar as pessoas em cárcere privado, amarradas ou trancadas, o que é uma cena comum

\footnotetext{
(3) Goffman (1974) cunhou o termo Instituições totais para designar as instituições fechadas que mantém uma barreira à relação social com o mundo externo, administrando a vida dos internos em todos os âmbitos. Nelas, todas as atividades da vida se dão num mesmo espaço físico e sob determinadas regras.
} 
e freqüentemente presenciada por agentes de saúde dos programas de saúde de família, por exemplo.

A lógica do abandono prevalece e se soma à insegurança vivenciada. Se o Estado e depois a empresa, e depois a família, dizem ao indivíduo que agora não estão interessados em seu destino, na direção de seus passos atuais e futuros, ou seja, se se abre mão de um tipo de abordagem que, através da disciplina, gerava segurança e estabilidade, ainda que fossem uma segurança e estabilidade subalternizadoras, o mesmo indivíduo cai no buraco cinzento e vazio da angústia e da insegurança, no movimento obsessivo e compulsivo de pedir autoridade, de pedir que cuidem dele, que continuem existindo por ele.

É por isso que muitas pessoas com sofrimento psíquico grave que vivem processos de desinstitucionalização resistem em sair do hospital para viver em residências terapêuticas ou mesmo com suas famílias. Não é só por terem esquecido de como lidar com a própria liberdade, mas porque o deserto de relações e de sentidos de vida com que se deparam quando em contato com os territórios de existência não os deixa vislumbrar possibilidades promissoras de existência.

Todas as estratégias do Estado e da sociedade para garantir um novo enraizamento, substituindo as formas medievais de pertencimento servo-senhor, as instituições, os valores e práticas do trabalho, essas mesmas estratégias é que estão sendo superadas, ou melhor, saindo do campo do fornecimento de respostas, e produzindo a insegurança atual (BAUMAN, 2003; CASTEL, 1998).

$\mathrm{E}$, nesses termos, o manicômio não precisa produzir tecnologias sofisticadas para garantir o manejo e os resultados terapêuticos. Ele passa a ser um espaço de refugo pós-moderno de portas giratórias semifechadas, onde a antiga e problemática ética do cuidar imposta e delegada à psiquiatria perde parte de seu sentido quando se delega o controle não tanto à disciplina, mas ao abandono.

Assim se atualizam os processos nos quais Basaglia identificava a função da psiquiatria como funcionária de um tipo de sociedade em que o valor não é o homem em sua singularidade, mas os processos econômicos, em que ele identificava a construção da ideologia médica. Ideologia por propor construções teóricas atreladas unicamente à manutenção dos termos da dominação, sem qualquer vínculo com as necessidades reais dos pacientes. Mas esse é um controle que se dá pelo abandono e não mais pela disciplina, como ocorria nos primeiros hospitais psiquiátricos, embora ainda se baseie na pobre e abstrata grade nosográfica construída em torno da noção de doença mental (BASAGLIA, 1985; BASAGLIA; BASAGLIA, 1977). Mantém-se a correspondência na lógica de funcionamento entre as estruturas do desenvolvimento econômico e as instituições: à estratégia de abandono nas relações de produção corresponde o abandono como tática do manicômio.

Parece então, que o hospital psiquiátrico é hoje um refugo, que continua a existir na inércia dos acontecimentos, não se sabe até quando. Contudo, contraditoriamente, ele parece continuar a ser muito necessário.

No entanto, na realidade brasileira, outras instituições vem ocupando um lugar de afirmação da pertinência do controle por meio da segregação. Estas instituições, ironicamente chamadas de comunidades terapêuticas, mas que em nada se assemelham às comunidades terapêuticas inglesas do pós-guerra, tentam selar a aliança entre as organizações religiosas e a ciência, embasadas na retomada de valores disciplinares em contextos de desregulamentação e formas high-techs e delicadas de controle (DELEUZE, 1992). De fato, a questão das drogas, trazidas à cena com a emergência da questão do crack, tem servido como baluarte de campanhas higienistas e moralistas, que fazem retornar à cena uma espécie de tratamento moral pós-moderno. Contudo, o combate às drogas, tem representado uma nova arma de manutenção do equilíbrio das relações sociais de dominação. A construção artificial da 'epidemia do crack' expressa a tentativa reativa de contornar movimentos de transformação social. Quando algo está a mudar e colocar em risco a dinâmica social, são estabelecidos os novos inimigos da ordem.

O movimento contínuo de desorganizaçãoorganização que mantém as estruturas sociais numa relação permanente de equilíbrio-desequilíbrio utilizando-se das anomalias, sente-se ameaçado quando as ondas de poder sugerem a superação da forma atual. Como ressaltam Deleuze e Guattari (2010), o capitalismo ou qualquer sistema político necessita de movimentos contestatórios e desorganizadores exatamente para reforçarem a necessidade de ordem, legitimarem a sua própria ordem. Mas aquilo que é essencial para a manutenção e fortalecimento do sistema, as próprias contestações, é o que pode provocar a sua morte, ou a sua metamorfose, transformando-o naquilo que ele não é. $O$ combate às drogas com seus dispositivos de controle será, possivelmente, um dos novos inimigos dos movimentos sociais e dos atores que constroem a reforma psiquiátrica no Brasil.

\section{Do abandono à produção de vida: problematizando o poder e superando a sociabilidade da mercadoria}

Para finalizar se levanta um problema que surge como um desafio teórico-prático à reforma psiquiátrica. 
Essa questão se refere ao padrão de sociabilidade produzido sob a influência do fetiche da mercadoria e à necessidade de lidar com a questão das relações de poder como algo central nos processos de desinstitucionalização e de crítica ao paradigma psiquiátrico tradicional (KURZ, 1993, FOUCAULT, 2003,a,b; ROTELLI, 1990).

Basaglia $(1985$, , esclareceu que o que estava por trás do desenvolvimento da psiquiatria e de suas instituições eram os processos econômicos. As formas de dominação - mais suaves ou mais pesadas, diretas e transparentes ou ocultas em sua apresentação e performance - estavam subordinadas a esses processos.

Ocorre que os processos econômicos, e a dominação que geraram, sempre estiveram submetidos a uma necessidade de tudo tornar abstrato e desprovido de sentido, a mesma contradição que Basaglia apontava ao se referir às necessidades reais versus as necessidades artificiais. Em todo esse tempo de modernização das civilizações, o objetivo foi fazer dos homens quantidades de trabalho abstrato que se relacionam entre si, como um fim em si mesmo e, portanto, sem possibilidade de existir projetualidade. Uma lógica da reificação, em que tudo, do afeto ao contato com o meio ambiente, se torna mercadoria. A mercadoria tornou-se uma presença onipotente, tendo no trabalho seu mais nobre súdito ou seu mais poderoso instrumento. Aos projetos de vida se sobrepôs o fim em si mesmo da valorização do valor, para usar a linguagem de Kurz (1999).

Para Kurz (1999a), no que se refere às formas de dominação,

o fato de os sujeitos-mercadoria utilizarem-se reciprocamente para os seus objetivos individuais não é o X da questão e muito menos a sua explicação. Antes, é a mera forma fenomênica de algo diverso - a saber, do fetiche sem sujeito - que se manifesta nos sujeitos que agem. Seus objetivos individuais não são o que parecem ser; segundo a sua forma, não são objetivos individuais e voluntários, e por isso também o conteúdo é distorcido e desemboca na autodestruição. $\mathrm{O}$ essencial não é os indivíduos se utilizarem mutuamente para seus objetivos individuais, mas sim, na medida em que parecem assim fazer, executarem em si mesmos um objetivo totalmente diverso, supra-individual e sem sujeito: o movimento autônomo (valorização) do capital (p. 9).

No que tange ao tema das instituições que servem a dominação, Basaglia (1977, p. 79) lembra também que

As ideologias científicas e as instituições tem a tarefa de garantir esta manipulação, unindo no mesmo jogo (apesar de, obviamente, com graus diferentes de possibilidades e de alternativas) a manipuladores e manipulados, controladores e controlados, uns através da identificação com seu papel, aparentemente ativos e autônomos, outros no sofrer aquilo que não têm a possibilidade de rechaçar.

Ou seja, dominados e dominadores, explorados e exploradores, funcionários do consenso ${ }^{(4)} \mathrm{e}$ seus objetos de intervenção, todos são submetidos a formas de dominação pouco conscientes (BASAGLIA; BASAGLIA, 1977).

Por caminhos que até certo ponto se cruzam com os de Basaglia, mas que também se desencontram destes, Michel Foucault analisa a dominação a partir das relações de poder. Desta vez, não se trata tanto de um poder absoluto, perene e de uma só direção, representado pelo Estado ou pelos aparelhos de Estado, na manutenção e proteção dos interesses econômicos, mas de um poder que se encontra em forma de relações de força e por toda a parte, desde microrrelações e microlutas, até nas grandes estratégias do Estado. Esse poder, sempre instável e em permanente relação com resistências que surgem como contrapoder, e que, dessa forma, direcionam o poder e lhe conferem forma e lugar, pode ser manipulado pelas grandes estratégias dos aparelhos de Estado para a dominação, pelas instituições, mas não pode ser explicado apenas como sendo dependente delas (FOUCAULT, 2003, 2003a,b).

Se o grande poder do Estado e das instituições pode enraizar-se nos microporos da sociedade, é porque microrrelações produzem excessos de poder na mesma direção, mobilizados mais pelo desejo que pelo simples interesse (FOUCAULT, 2003, 2003a).

O poder, para Foucault (2003), é o grande problema e a grande questão do século XX. Se o grande problema que mobilizou a investigação teórica no século XIX foi a exploração econômica e a miséria dela decorrente, explicando o excesso de poder da época, deve-se dizer - e é Foucault quem o faz - que no século XX já não é possível explicar o excesso de poder somente por causas econômicas.

Nessa caracterização do poder, não apenas na linha de um poder soberano do Estado, mas de um poder localizado em micro e macrorrelações, Foucault aponta aspectos sobre o poder importantes para a presente discussão:

\footnotetext{
(4) Basaglia e Basaglia (1977) utilizam a noção gramsciniana de ‘funcionários de consenso' para realizarem uma crítica ao papel dos profissionais de saúde mental legitimados socialmente pelo paradigma psiquiátrico. Os funcionários do consenso são os empregados da classe dominante para o exercício das funções subalternas da hegemonia social, ou seja, para a produção do consenso 'espontâneo' das massas em torno dos valores dominantes, bem como para o exercício da força e da repressão nos momentos de crise, quando o consenso não se dá de forma espontânea.
} 
$[\ldots]$

- que seu entrecruzamento delineia fatos gerais de dominação, que esta dominação se organiza em estratégia mais ou menos coerente e unitária: que os procedimentos dispersados, heteromorfos e locais de poder são reajustados, reforçados, transformados por essas estratégias globais, e tudo isso com numerosos fenômenos de inércia, de intervalos, de resistências; que não se deve, portanto, pensar um fato primeiro e maciço de dominação (uma estrutura binária com, de um lado, os "dominantes" e, do outro, os "dominados"), mas, antes, uma produção multiforme de relações de dominação, que são parcialmente integráveis a estratégias de conjunto;

- que as relações de poder "servem", de fato, porém não porque estão "a serviço" de um interesse econômico dado como primitivo, mas porque podem ser utilizadas em estratégias;

- que não há relações de poder sem resistências; que estas são tão mais reais e eficazes quanto mais se formem ali mesmo onde se exercem as relações de poder; a resistência ao poder não tem que vir de fora para ser real, mas ela não é pega na armadilha porque ela é compatriota do poder. Ela existe tanto mais quanto ela esteja ali onde está o poder; ela é, portanto, como ele, múltipla e integrável a estratégias globais.

A luta de classes pode, portanto, não ser a "ratio do exercício do poder" e ser, todavia, "garantia de inteligibilidade" de algumas grandes estratégias. (Foucault, 2003b, p. 248-9)

Se se associa a crítica à dominação ampliando, como faz Foucault, à questão do poder, e se, como faz Kurz, se aceita que, como efeito do poder, existe toda a produção de uma sociabilidade vinculada à lógica da mercadoria, vê-se que $\mathrm{o}$ fato de os processos de reforma psiquiátrica colocarem o tema da singularidade e da liberdade no centro do debate garante por certo um lugar especial nos questionamentos da dominação. (FOUCAULT, 2003, 2003a,b; KURZ,1999a)

Mas, segundo esse viés, tais questionamentos podem estar limitados, se a sociabilidade pela forma-mercadoria não é enfrentada e radicalmente criticada, e se não se lidar com a questão do poder em seu exercício perene, presente também nas relações entre a ciência, seus profissionais e instituições, e no objeto de sua intervenção, ou seja, a pessoa com sofrimento mental.

A superação do manicômio e a desinstitucionalização, como processo complexo de desconstrução de saberes, práticas e valores (ROTELLI et al., 1990; NICÁCIO, 2003), deveria enfrentar a centralidade da presença da forma-mercadoria na vida de todos, já que essa presença fantasmática, do campo do fetiche, talvez esteja subjacente aos processos econômicos, envidando uma dominação sem sujeito (KURZ, 1999a). Enfrentar as contradições da realidade seria, então, nesses termos, identificar e enfrentar esse tipo de dominação que parece ter um importante papel na composição das demais formas de opressão.

Esse desafio, portanto, deve fazer parte das preocupações daqueles que questionam o paradigma psiquiátrico e o manicômio, para que este, tão vinculado à forma-mercadoria, possa ser superado.

KINKER, F. S. The place of the psychiatric hospital at the present time: from the discipline to abandonment. Rev. Ter. Ocup. Univ. São Paulo, v. 23, n. 2, p. 178-185, maio/ago. 2012.

\begin{abstract}
This paper presents a reflection about the position of the psychiatric hospital nowadays. Starting from the experience of deconstructing a psychiatric hospital in Campina Grande, Paraíba, in 2005, it discuss that the current mental hospitals don't really work from a disciplinary logic, which followed during many years the development of the asylum, but from a new logic of the abandonment, in synchrony with the new ways of deregulation that characterize the present pattern of sociability. The abandonment emerges as a method of controlling the segregating institutions that is in agreement with the new deregulated forms of control. At last, the need for a more critical thinking about the modern forms of sociability is discussed, as an important step toward the deconstruction of the psychiatric paradigm.
\end{abstract}

KEY WORDS: Deinstitutionalization; Psychiatric department, hospital; Health care reform.

\title{
REFERÊNCIAS
}

ANDERSON, P. Balanço do neoliberalismo. In: SADER, E.; GENTILI, P. (Org.). Pós-neoliberalismo: as políticas sociais e o estado democrático. 7a. ed. São Paulo: Paz e Terra. 2007. p. 9-23

BASAGLIA, F.; BASAGLIA, F. O. Los crímenes de la paz. 
In: BASAGLIA, F.; BASAGLIA, F. O. (Orgs.). Los crimenes de la paz: Investigación sobre los intelectuales y los técnicos como servidores de la opresión. Trad. Juan Diego Castillo con la colaboración de Maria Elena Petrilli y Marta E. Ortiz. Revisión técnica de Armando Suárez. Madrid: Siglo Veintiuno de España Editores, 1977. p. 13-102.

BASAGLIA, F. As instituições da violência. In: BASAGLIA, F. (Org.). A instituição negada. Trad. Heloísa Jahn. Rio de Janeiro: Graal, 1985. p. 99-133.

BAUMAN, Z. O mal-estar da pós-modernidade. Rio de Janeiro: Zahar, 1998.

BAUMAN, Z. Comunidade: A busca por segurança no mundo atual. Trad. Plínio Dentzien. Rio de Janeiro: J. Zahar, 2003.

BAUMAN, Z. Amor líquido: sobre a fragilidade dos laços humanos. Trad. Carlos Alberto Medeiros. Rio de Janeiro: J. Zajar, 2004.

CASTEL, R. La contradicción psiquiátrica. In: BASAGLIA, F.; BASAGLIA, F. O. (Orgs.). Los crimenes de la paz: Investigación sobre los intelectuales y los técnicos como servidores de la opresión. Trad. Juan Diego Castillo con la colaboración de Maria Elena Petrilli y Marta E. Ortiz. Revisión técnica de Armando Suárez. Madrid: Siglo XXI de España, 1977. p. 151-66.

CASTEL, R. As metamorfoses da questão social: uma crônica do salário. Trad. Iraci D. Poleti. Petrópolis: Vozes, 1998.

DELEUZE, G. Conversações. Trad. Peter Pál Pelbart. São Paulo: 34 Letras, 1992. p. 219-226.

DELEUZE, G.; GUATTARI, F. $O$ anti-édipo: capitalismo e esquizofrenia. Trad. Luís B. L. Orlandi. São Paulo: Ed. 34, 2010 (Coleção TRANS).

FOUCAULT, M. Vigiar e punir. 23a. ed. Trad. Raquel Ramalhete. Petrópolis: Vozes, 2000.

FOUCAULT, M. Poder e saber: Entrevista com S. Hasumi gravada em Paris, dia 13 de outubro de 1977, Umi, dez. 1977, p. 240-256. In: FOUCAULT, M. Ditos e escritos IV: Estratégia, Poder-Saber. Organizador: Manoel Barros da Motta. Trad. Vera Lúcia Avellar Ribeiro. Rio de Janeiro: Forense Universitária, 2003. p. 223-240.

FOUCAULT, M. Os intelectuais e o poder: Entrevista com G. Deleuze, 4 de março de 1972; L'Arc, n. 49: Gilles Deleuze, $2^{\circ}$ semestre de 1972, p. 3-10. In: FOUCAULT, M. Ditos e escritos $I V$ : Estratégia, Poder-Saber. Organização: Manoel Barros da Motta. Trad. Vera Lúcia Avellar Ribeiro. Rio de Janeiro: Forense Universitária, 2003a. p. 37-47.

Recebido para publicação: 15/06/2012

Aceito para publicação: 08/08/2012
FOUCAULT, M. . Poderes e estratégias: Entrevista com J. Rancière; Les Révoltes Logigues, n. 4, inverno de 1977, p. 89-97. In: FOUCAULT, M. Ditos e escritos IV: Estratégia, Poder-Saber. Organização: Manoel Barros da Motta. Trad. Vera Lúcia Avellar Ribeiro. Rio de Janeiro: Forense Universitária, 2003b. p. 241-252.

FOUCAULT, M. História da loucura na idade clássica. 8a. ed. Trad. José Teixeira Coelho Neto. São Paulo: Perspectiva, 2005. (Col. Estudos 61, dirigida por J. Guinsburg)

FOUCAULT, M. Microfísica do poder. 26a. ed. Rio de Janeiro: Graal, 2008.

GOFFMAN, E. Manicômios, prisões e conventos. Trad. Dante Moreira Leite. São Paulo: Perspectiva, 1974.

KINKER, F. S. O lugar do manicômio: relato da experiência de desconstrução de um hospital psiquiátrico no interior do Nordeste. 2007. 173f. Dissertação (mestrado). Pontifícia Universidade Católica de São Paulo. São Paulo, 2007.

KURZ, R. O colapso da modernização: da derrocada do socialismo de caserna à crise da economia mundial. 3. ed. Trad.: Karen Elsabe Barbosa. São Paulo: Paz e Terra, 1993.

KURZ, R. Pós-marxismo e fetiche do trabalho: sobre a contradição histórica na teoria de Marx. Trad.: Heinz Dieter Heideman. São Paulo: Laboratório de Geografia Urbana/ Depto. de Geografia/ FFLCH/USP, 1999. (mimeo.)

KURZ, R. Dominação sem sujeito: Sobre a superação de uma crítica social redutora. Trad.: Heinz Dieter Heideman. São Paulo: Laboratório de Geografia Urbana/ Depto. de Geografia/FFLCH/ USP, 1999a. (mimeo.)

NICÁCIO, M. F. S. Utopia da realidade: contribuições da desinstitucionalização para a invenção de serviços de saúde mental. 2003. 224f. Tese (Doutorado). Faculdade de Ciências Médicas, Universidade Estadual de Campinas, Campinas, 2003.

ROTELLI, F. Ainstituição inventada. Trad. Maria Fernanda de Silvio Nicácio. In: NICÁCIO, M. F. S. (Org.). Desinstitucionalização. São Paulo: Hucitec, 1990. p. 89-100.

ROTELli, F.; DE LEONARDIS, O.; MAURI, D. Desinstitucionalização, uma outra via: A reforma psiquiátrica italiana no contexto da Europa Ocidental e dos "Países Avançados". Trad. Maria Fernanda de Silvio Nicácio. In: NICÁCIO, M. F. S. (Org.). Desinstitucionalização. São Paulo: Hucitec, 1990. p. 17-59

SENNETT, R. A cultura do novo capitalismo. Trad. Clóvis Marques. Rio de Janeiro: Record, 2006. 